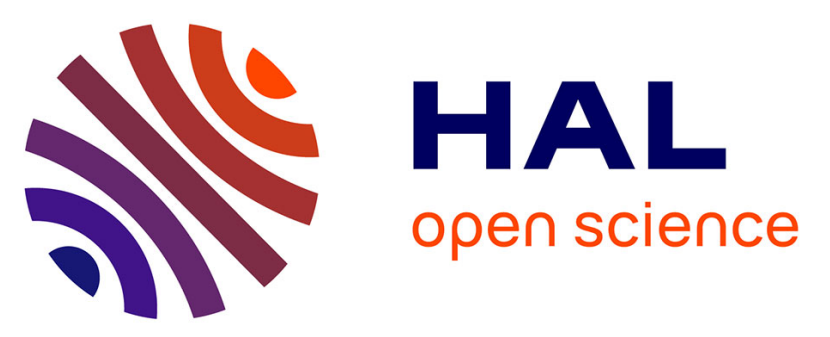

\title{
Accessibility of public urban space: considering the diversity of ordinary pedestrian practices
}

\author{
Rachel Thomas
}

\section{To cite this version:}

Rachel Thomas. Accessibility of public urban space: considering the diversity of ordinary pedestrian practices. Dissart Jean-Christophe; Seigneuret, Natacha. Local ressources, Territorial development and Well-being, Edward Elgar Publishing, pp.162-179, 2020, 978-1-78990-860-2. 10.4337/9781789908619.00018. halshs-02935201

\section{HAL Id: halshs-02935201 https://shs.hal.science/halshs-02935201}

Submitted on 10 Sep 2020

HAL is a multi-disciplinary open access archive for the deposit and dissemination of scientific research documents, whether they are published or not. The documents may come from teaching and research institutions in France or abroad, or from public or private research centers.
L'archive ouverte pluridisciplinaire HAL, est destinée au dépôt et à la diffusion de documents scientifiques de niveau recherche, publiés ou non, émanant des établissements d'enseignement et de recherche français ou étrangers, des laboratoires publics ou privés.

\section{(1)(1) $\$(0)$}

Distributed under a Creative Commons Attribution - NonCommercial - ShareAlikel 4.0 


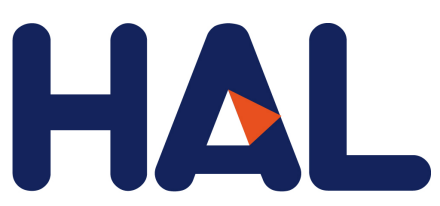

archives-ouvertes

\section{ACCESSIBILITY TO PUBLIC URBAN SPACE: THINK ABOUT THE DIVERSITY OF THE ORDINARY PEDESTRIAN PRACTICES}

Rachel Thomas

\section{- To cite this version:}

Rachel Thomas. ACCESSIBILITY TO PUBLIC URBAN SPACE: THINK ABOUT THE DIVERSITY OF THE ORDINARY PEDESTRIAN PRACTICES. Dissart Jean-Christophe; Seigneuret, Natache. Local ressources, Territorial development and Well-being, Edward Elgar Publishing, pp.162-179, 2020, 978-1-78990-860-2. 10.4337/9781789908619.00018 . halshs-02935201

\section{HAL Id: halshs-02935201 https://halshs.archives-ouvertes.fr/halshs-02935201}

Submitted on 10 Sep 2020

HAL is a multi-disciplinary open access archive for the deposit and dissemination of scientific research documents, whether they are published or not. The documents may come from teaching and research institutions in France or abroad, or from public or private research centers.
L'archive ouverte pluridisciplinaire HAL, est destinée au dépôt et à la diffusion de documents scientifiques de niveau recherche, publiés ou non, émanant des établissements d'enseignement et de recherche français ou étrangers, des laboratoires publics ou privés.

\section{(1)(1) $\$(0)$}

Distributed under a Creative Commons Attribution - NonCommercial - ShareAlikel 4.0 


\title{
ACCESSIBILITY OF PUBLIC URBAN SPACE: CONSIDERING THE DIVERSITY OF ORDINARY PEDESTRIAN PRACTICES
}

\author{
Rachel THOMAS \\ Univ.Grenoble Alpes \\ CNRS UMR 1563, School of Architecture, CRESSON
}

\begin{abstract}
Since thirty years in France, the accessibility to public urban space became a major challenge for the planning of cities and the improvement of the quality of life of city dwellers. But the approaches continue to be standards approaches and they encourage a proliferation of isolated technical devices for disabled people. This paper suggest to approach the accessibility through the field of the architectural and urban ambiences, from the diversity of the ordinary pedestrian practices. It shows how pedestrian accessibiliy depends on a perceptual and situated achievement. It introduces the idea of "sensory configuration". The pedestrian's configuring activity involves in taking hold of, associating and finally appropriating resources (visual, bright, sound, tactile, thermal... resources) afforded by the sensory environment. This activity enables pedestrians to decode their immediate surroundings, to orient themselves and finally to adjust their behaviour to the urban situations.
\end{abstract}

Keywords: Accessibility; ambiences; disability; disabling situations; pedestrian; quality of life; urban public spaces.

\section{Introduction}

Over the past thirty years in France, approaches about pedestrian accessibility to public urban space have evolved. Consequently, its reception in the fields of architecture and town planning improves, the accessibility being included now as one of the qualities of urban life (Talen, 2002), as an element of a 'politics of conviviality' (Hinchliffe and Whatmore, 2006). Two reasons explain this evolution. On one hand, the ageing French population and its associated disorders (difficulty walking, impairment of memory, loss of vision and/or hearing...) questions the planners about the adaptation of the urban public places. As other city-dwellers, they express the same needs for autonomy, for recognition, for hospitality, for user-friendliness and to make more of a contribution to the community (Katz et al., 2011). With the question of disability, the ageing population has become a high stake for city planning policies. A second reason explains this renewal of thought about accessibility in France: in February 11th, 2005, the legislation $n^{\circ} 2005-102$ "for the equality of the rights and the chances, the participation and the citizenship of the disabled people" was enacted by the government. Now, this legislation addresses accessibility in terms of user comfort, establishes new rules of conception and sets up financial penalties if the standarts are not respected.

This article provides a background and a review of assistive devices to conceptualize an adapted urban public places. It offers a critically argued look at these evolutions, by showing that it favors a technical approach of the accessibility, centered on the disabled person. Developed since the research field of architectural and urban ambiences wich promote a sensitive approach of the built environment, this criticism adopts the opposite stance to the concepts advanced until now on accessibility, defending two ideas.

The first one is that pedestrian access to the city is the result of a practical, perceptual process of taking root. It is never predetermined by the spatial qualities. It is being constructed during the walk. Such an assertion has an empirical basis. In the field of architectural and urban ambiences, we consider that the understanding of the links between the city dweller and his environment requires situated and multisensory 
approaches. Against spatialist and normative approaches - which are often based on "aboveground" and decontextualized hypothesis - we favor the field survey. In each of our approaches, we pay attention to the perceptual activity of the pedestrian, his sensations and the qualities (physical and sensory) of space. In this work on accessibility, our field surveys have taken the form of walking courses with various publics (disabled, elderly, congested, accompanied by children, suffering from vascular problems or pregnant ...) and observations of ordinary walking situations. These courses and observations took place in Grenoble (France), Athens (Greece), Prague (Czech Republic) and Copenhagen (Denmark) between 1997 and 2005. A researcher accompanied a pedestrian on a daily journey (during approximatively one hour) or followed him, in the spinning mode. The aim of this survey was to understand the different tactics used by pedestrians to make their journey and adapt themselves to difficult situations like the presence of physical obstacles or the crowd, the existence of intense events, problems of orientation etc. In other words, we are not only focusing on architectural barriers. We broadened our questions to the role of sounds, light, floor coverings ... on the comfort of mobility.

The theme of mobility is still central to debate on pedestrian accessibility to the city. But, in this line of thought, mobility is often still seen in terms of a succession of physical mechanisms: moving or being mobile is a matter of demonstrating one's capacity to change position in space. From this standpoint, thinking on pedestrian accessibility to the city boils down to the conditions under which it is possible to achieve movement. In practice, recent town planning schemes have sought to reduce the number of physical barriers to movement, increase the legibility of space (in particular by harmonizing signing) and encourage connections between the various means of transport. We defend a slightly different point of view. Mobility, we would suggest, cannot only be seen in its physical dimension. Because walking also plays a part in chance encounters between anonymous people, it also constitutes a form of urbanity (Goffman 1963, 1971; Whyte, 1980; Solnit, 2001; Augoyard, 2007; Holland et alii, 2007) and 'an aesthetic practice' (Careri, 2002). This is based on both compliance with the rules of civility in public, on the physical and sensory qualities of the built environment, on the motor and perceptual skills of the pedestrian, and lastly on the specificities of the social milieu in which he or she is integrated. So, this requires us to think about and reveal the permanent process of adjustment between the pedestrian's perception, and how the (physical, social and sensory) resources of both the environment and the action underway are used. From this perspective, pedestrian accessibility to the city is not so much a matter of architectural barriers to movement or various individual disabilities, but rather a question of the poor match between the resources present in a given place, and the pedestrian's perception and action.

The second hypothesis which we suggest developing concerns the way of thinking disability. The question of disabilities, and more specifically of how to alleviate physical disabilities, is still uppermost in current debate about accessibility. However, only partial allowance is made for sensory deficiency, particularly for hearing; allowance for mental disabilities is marginal (Blackman et al., 2003). But it is seen in terms of organic deficiency: the 'disabled' are often defined as people whose physical or mental integrity has been gradually or permanently diminished, either congenitally or by aging, illness or accident, with the result that their autonomy, aptitude to go to school or do a job is compromised. For the disabled, access to the city is therefore conditional, depending on their disability, on it being alleviated or the physical barriers in its way being removed.

We hold that it is no longer sustainable to conceptualize urban accessibility in terms of disabilities. The limitations of this approach, both with regard to urban design and the perception of the disabled, are manifest. It is time to question, not so much the shortcoming itself as the skills required of pedestrians and what they reveal about the city. The experience of the physically disabled as they make their way shows that the 
design and surface of streets encourage the development of motive potentialities; as drivers or pedestrians, the experience of the blind and visually impaired is testimony to the help provided by the city's sonic environment and sometimes by contrasting colours and lights (Coulter and Parsons, 1990; Bordreuil, 2005; Thomas 2005, 2010). Policymakers and planners have neglected these intrinsic qualities of the urban space for too long, or at best treated them as minor details (Imrie and Kumar, 1998; Van der Linden et alii, 2016) while it constitutes one of essential element of a politics of urban public spaces (Low and Smith, 2006). Our purpose is, on the contrary, to draw attention to them and highlight their role in affording access to the city for all pedestrians, ultimately making explicit the conceptual and empiric issues our position raises. We think also that a detour via the experience of disabled people as they travel from A to B offers a heuristic tool for conceptualizing accessibility for all to the public urban space.

\section{Disabling urban situations}

Thinking on the accessibility of public urban space, and the adoption of a regulatory framework, was instigated in France in the 1970s by social unrest, in particular the revolt of the motor-disabled against architectural barriers to their movement. Such obstacles were numerous: raised platforms or steps at the entrance to many public buildings; steeply sloping or tilting streets; profusion of street furniture, often badly placed; pavements too high to be mounted by wheelchairs; and so on. The revolt gathered strength when the motor-disabled were joined by the sight-impaired, and then by a host of other people with difficulties getting about. The list of material constraints on movement grew longer, focusing attention on issues with urban signing and legibility. At the same time the disabled gained greater visibility, calling into question a society which had kept them out of the public eye, cloistered within specialist institutions (Fig.1). Furthermore, they raised the question, for an urban world, of how to obtain autonomy and social recognition and to develop their well-being through access to the city.

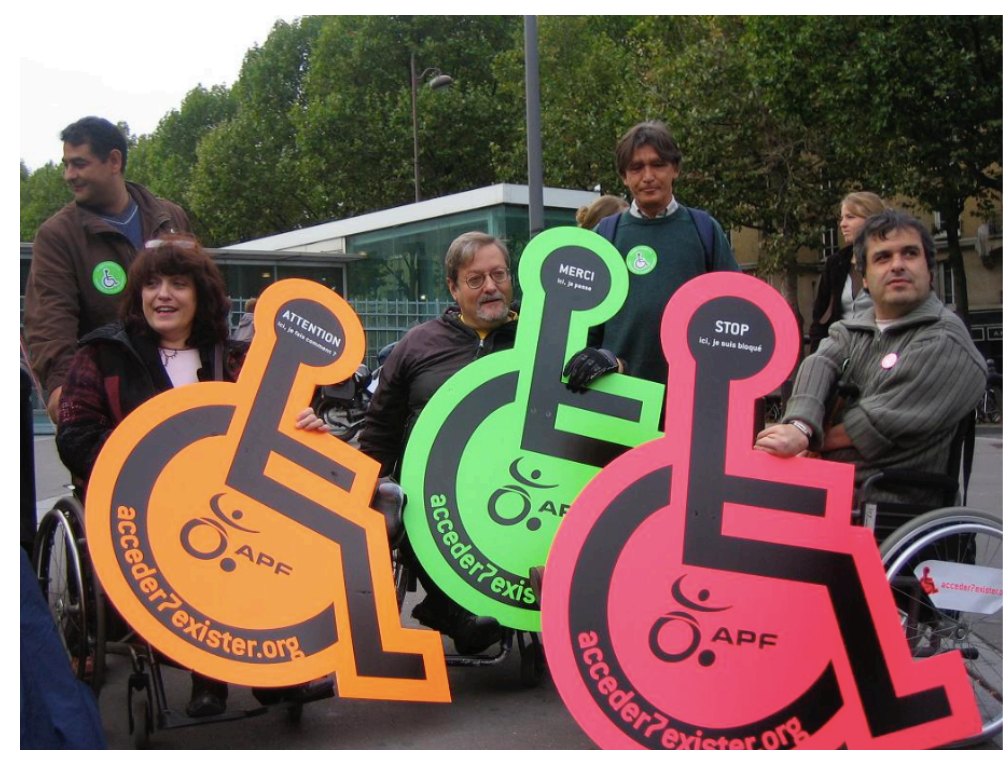

Fig. 1 - In 2008 in Paris, the Association des Paralysés de France is launching the 2nd edition of its 'Access to Exist' awareness campaign, one of the objectives of which is to denounce architectural barriers to the movement of people with disabilities. The principle of action is simple: implant life-size silhouettes whose color says the accessibility of the places. Green for easy access, orange for obstacle access, red for inaccessibility without external help. 
The response to this social and regulatory pressure by urban-design professionals has come in two stages. Starting in the mid-1980s, minimalist application of the new regulations prompted them to try to alleviate physical and/or sensory disabilities. In practice this policy entailed the creation and installation in cities of 'architectural prostheses' to assist movement by the disabled. These physical or conceptual devices were added to the existing space, limiting the constraints on movement due to a disability, an architectural barrier or defective signing. Their prime characteristic was their specialization, with a specific device to alleviate each type of disability. In this way widespread use of 'bateaux', or dropped kerbs, and 'oreilles', or kerb build-outs at junctions assisted movement by people in wheelchairs: by lowering the edge of the pavement and/or reducing the width of the road, designers made it easier to cross (Fig.2). They also sought to increase safety for the sight-impaired or blind, making it easier to find their way by laying tactile tiles on the pavement for hazard warning and directional guidance (Fig.3). Such tiles differed in their form and purpose. Hazard warning strips generally consisted of a rectangle, with a rough surface marked by grooves or bumps. They were placed before dropped kerbs, the start of an escalator or staircase, on the platforms of tram, subway or train stations. When detected either by the feet or a stick, they warned of a potential hazard. Such warning strips in France must comply with the NF P98-351 standard. Since 2007, the presence of these devices is compulsory upstream to the pedestrian crossings and along the platforms of urban transport.
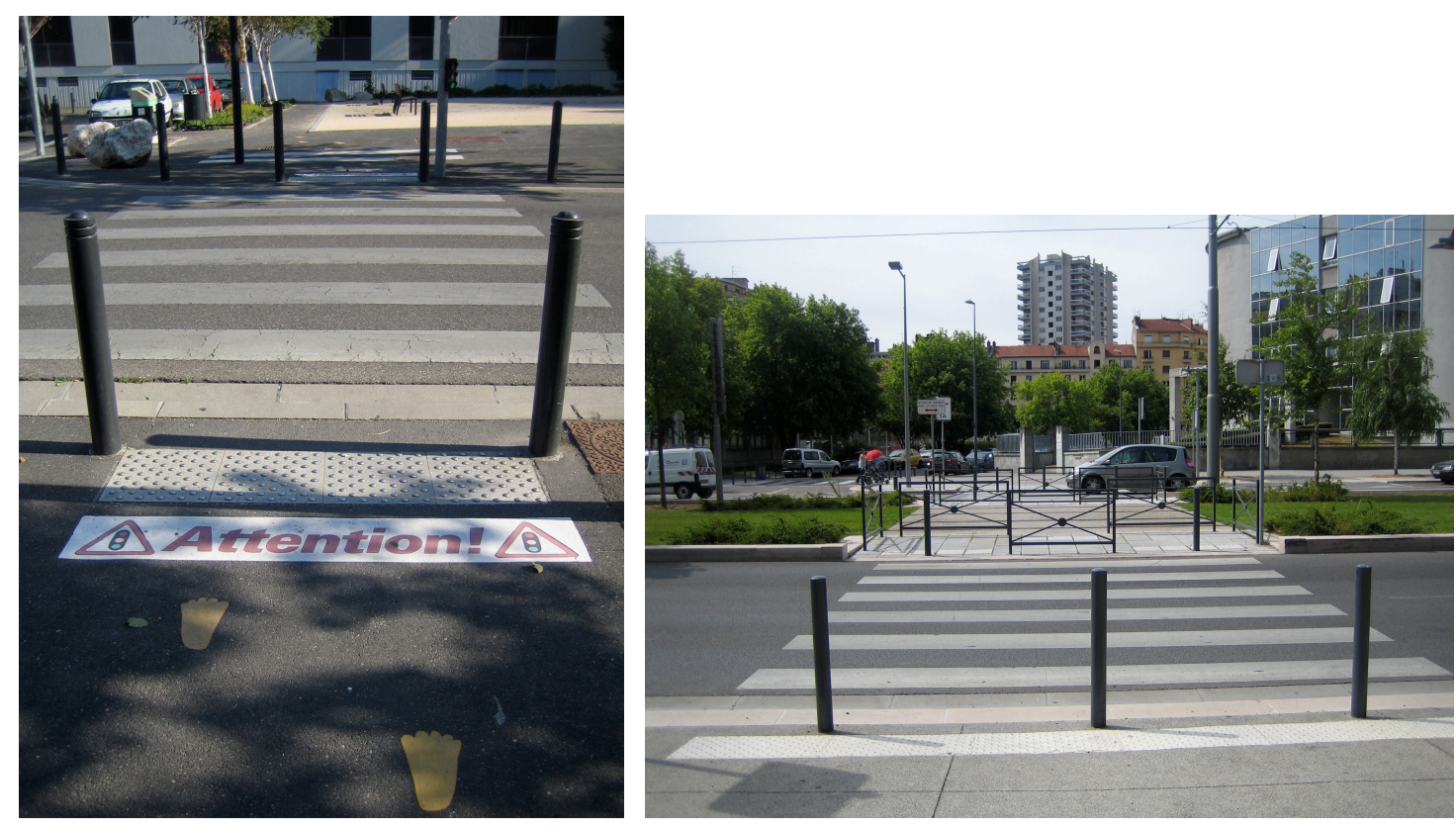

Fig. 2 \& 3 - Two examples of 'bateaux' and hazard warning strips at pedestrian crossings (c) Rachel Thomas)

Directional strips were marked by hollowed out or raised grooves or elastomer adhesive tape. They provided directional guidance for the sight-impaired, who could keep track of them with a stick, moving from A to B (Fig. 4 \& 5). Since 2014, they must comply with the NF P98-352. 

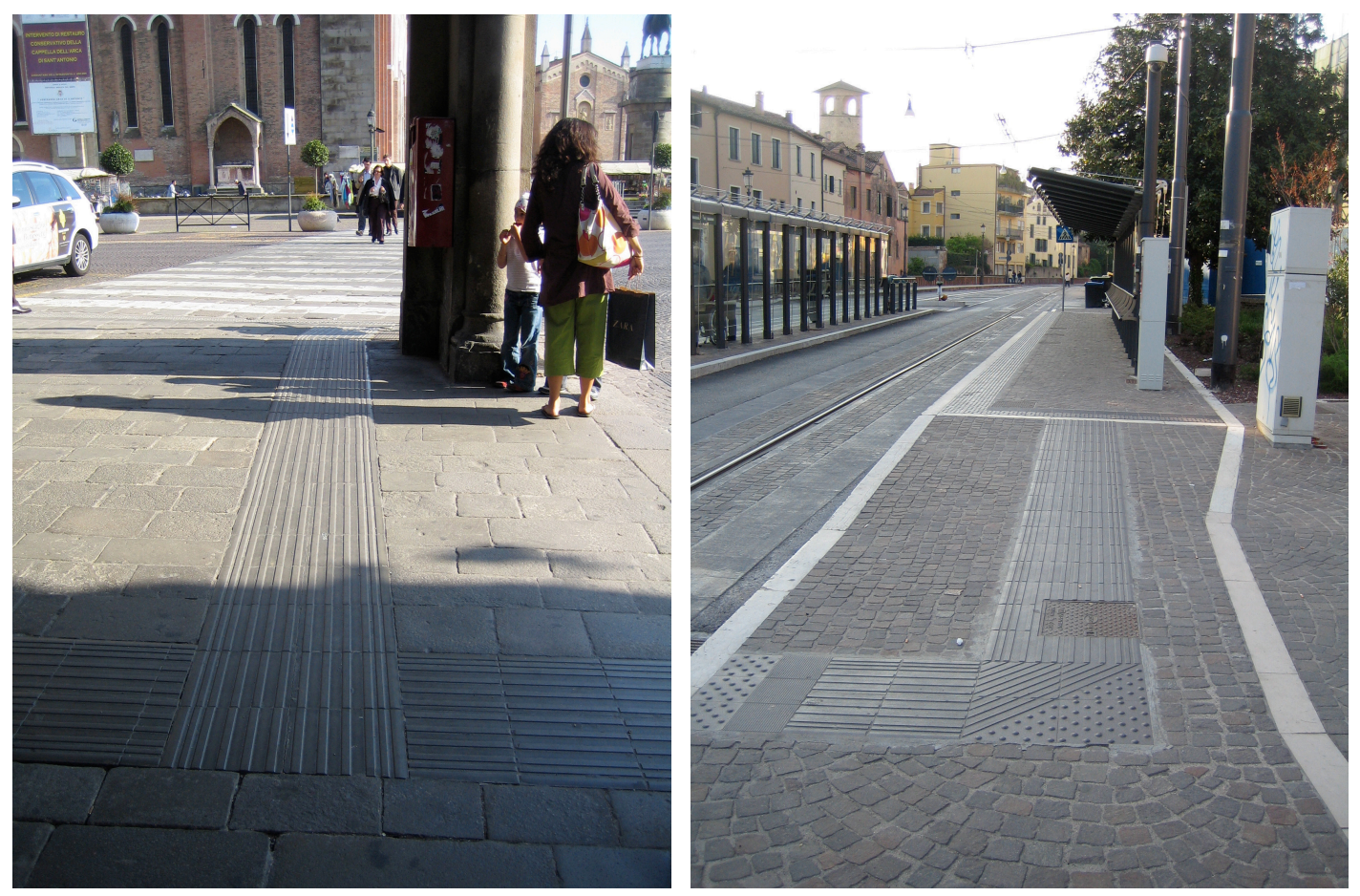

Fig. 4 \& 5 - Directional strips before pedestrian crossings / Directional strips and hazard warning strips on a platform of tram

(C) Rachel Thomas)

At road crossings, these devices were generally supplemented by audible signals coinciding with pedestrian lights: a loudspeaker or transmittersinformed pedestrians that they could step out onto the pedestrian crossing and get across safely. For example the EO guidance system, designed by the French society 'Études et Développement de Produits et Services', operates as follows: a microchip receiver is built into pedestrian cues; sight-impaired pedestrians carry a remote-control which can trigger the receiver. Once activated the system produces two types of sound message: the name of the street being crossed and the colour of the pedestrian light.

Use of this technology has now become widespread, particularly to assist difficulties finding one's way due to a sight disability. It is part of a new approach adopted by designers, which involves erasing any urban situation likely to constitute a handicap and increasing a better quality of life. This means identifying, understanding and lastly eliminating features of the surroundings which hinder the continuity of movement and prevent people from finding their way. So, the handicap concept is still present, but in a different form. The concern now is to highlight such 'situational' handicaps posed by a given space to those using it. In practical terms this determination to achieve accessibility for all results in 'smoothing' of space: the ground is flattened out, visual and sound signing is enhanced, the disposition of street furniture must comply with strict standards on alignment and number, and pedestrian routes are secured.

The proliferation of these isolated technical devices has remedied the most common problems impeding movement. But this trend has also affected the design of cities and thinking on handicaps. Firstly, the problem of competition between the senses remains unresolved; competition between individual items of furniture seems to have been exacerbated. Numerous works (Imrie and Kumar, 1998; Thomas, 2005; Lauria, 2017) has shown that dropped kerbs have had a positive impact on movement by people with limited mobility but have disoriented the sight-impaired. Reducing the rise on a dropped kerb avoids the risk of an accident for wheelchair users but deprives the sight-impaired of cues on the ground. On complex road crossings (with a large number of traffic flows 
and sound signals), this 'blandization' of the podo-tactile space forces the sightimpaired (due to the loss of cues it entails) to venture across the road unassisted. Secondly these tools singularize disabled persons with regard to their particular disability and distinguish them from a 'normalized' framework of locomotion (Fig.6). By drawing a distinction between various forms of disability and differentiating locomotion by the disabled from that of ordinary pedestrians, the new approach to street design suggests that there are marginal walking practices (Kitchin, 1998; Lauria, 2017).
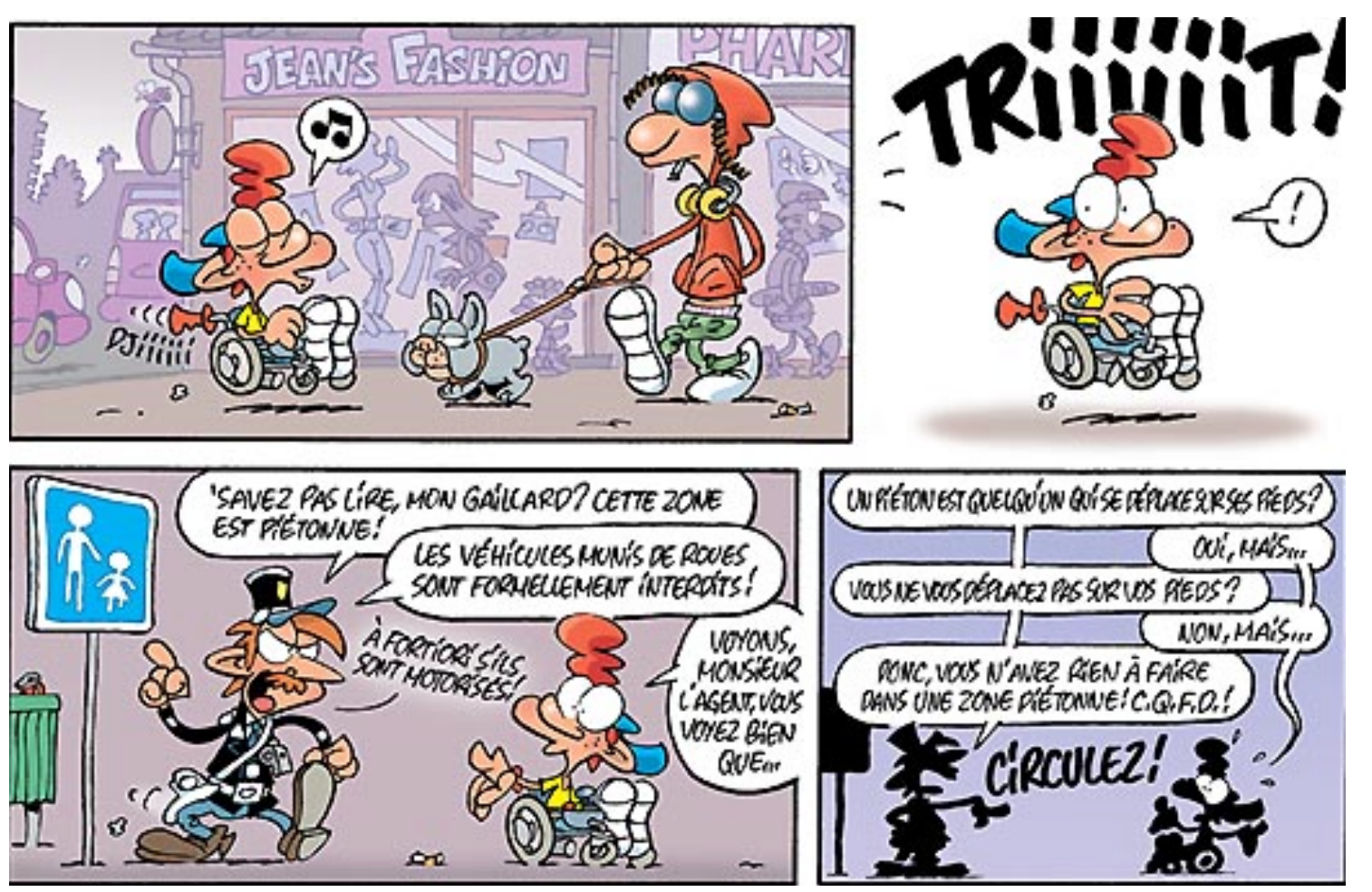

Fig. 6 - Extract from the comic book 'Schumi, 2': 'normalized' framework of locomotion and distinction between various form of locomotion in urban public space

Script : Benoit Drousie - Publisher : Paquet, 2012

These practices would necessitate the creation of specific technical places, passages and/or systems. This sort of conception is surely open to dispute. With longer life expectancy and the temporary incidents inherent in human life we are all confronted with situations of disability. For example, in common with wheelchair users, people pushing a stroller have difficulty mounting a pavement, getting onto transport and entering public buildings.

Lastly all these devices, by creating set routes, functionalize urban travel: the routes made accessible in this way generally lead those taking them to carry out useful tasks (shopping, administrative formalities, healthcare, etc.). In this sense pedestrian journeys are reduced to their practical finality. Surely, we may imagine other purposes and timeframes for walking in the city? For example, what about aimless strolling through the city during which pedestrians may sometimes search out its least known spaces? What about the hordes of shoppers who tramp through the streets when the sales are on? How do these ordinary, plural ways of moving about and gaining access to the city coexist? What features of the environment and what skills do they bring into play on the part of the pedestrian? 


\section{Resources designed to respond to movement}

After focusing on public sociability (Goffman 1963, 1971) for many years, social scientists are now taking an interest in the issue of urban mobility. Two main schools of thought have emerged, opening the way for some controversy. The advocates of an ecology of perception have turned to a notion originally developed by Gibson (1979) as part of his analysis of visual perception, addressing the subject in terms of 'action affordances': any perceiving subject extracts from their position in space the information needed to accomplish their action. The work of Levy (1994), Sanchez and Velche (1996) on stations and Mehta on walkable streets (2008), demonstrates the part played by the surroundings in the direction and continuity of movement: each device (ticket office or machine), service (toilets, telephones, bar), sensory input (sign, public address) in a given space may represent an aid or an obstacle for a pedestrian's locomotion and information. Their nature depends on both their position in space, their connection to the current action and the pedestrian's ability to make use of them in a set space-time framework.

Study of transport hubs reveals three typical situations - which seem to exist and occur in exactly the same way in public urban space - and discuss the notion of "affordance". In the first situation, the environment provides pedestrians with the resource they require: a public-address announcement and/or visual display reassures hurrying travellers by confirming the time and platform of their train. In this case, movement is continuous.

In the second situation, there is a hiatus between the information required and the resource afforded by the surroundings. For example, the public-address announcement does not concern the train our hurrying travellers want to take. Movement is consequently slowed; the travellers being obliged to seek guidance from some other medium.

Lastly, the third situation is subject to constraint, the environment failing to respond to the demands of travellers. Neither the public-address announcement nor the visual display tell them anything about their train. The travellers must consequently find another source of information, running the risk of missing their train.

In each of these cases the notion of a disability disappears, driven out by a disabling urban situation. This refers less to the idea of an organic deficiency in the individual, rather to the built environment being ill-suited to the action. A disabling situation may thus occur in two circumstances: when the design of spaces is totally unsuited to the demands of users; or when the latter have difficulty mobilizing and appropriating a place's facilities. From this point of view, the idea of action affordances changes to take on an ambivalent character: space as it is built, objects as they play a part in the design of a place are as many resources or obstacles to pedestrian progress. They 'do not exist [...] as such in reality; it is when they are mobilized, at the point in time when they are contextualized, that they make sense' (Levy, 1994: 44). Furthermore, a resource only exists as a function of the perceiving subject, of his or her action and position in space.

Approaches of this sort enable us to refocus debate on urban accessibility on the environment and design of space. Architecture, but also street furniture, road surface, some visual and audible signals help create disabling situations or conversely, are facilitating elements. However, these approaches do leave some questions unanswered.

The first one relates to the sensory nature of movement. According to the theorists of the ecology of perception, the sensory modality may be reduced to its environmental dimension. According the surface qualities of objects (texture, colour, etc.) or space constitute resources or obstacles for action (Mehta, 2008; Jenkins et alii, 2015). Although we are told that these resources are built in a dynamic of movement, no 
information is forthcoming on the type of perceptual activity which underpins efforts to find them. Do pedestrians anticipate the presence of potential resources in a space and memorize their position, or do they go about selecting such resources? Is the process of looking for resources linked to a particular type of motor activity or is it common to all forms of locomotion? In other words, can one go further in specifying the links between the environment, the perceptual activity of pedestrians and locomotion? The second problem posed by this type of approach is due to its restrictive conception of the role and nature of the sensory modality. The latter only seems to act as a vector for information to pedestrians, for use in the immediate control of their action. In addition, this information-seeking role is largely dependent on the visual modality. But what about sonic, tactile, thermal, olfactive and atmospheric material? Do these forms of material engage pedestrians' perceptual and motor activity? If so, in what way? Does the specificity of each of the senses also play a part in the way space is grasped during a journey?

Lastly this type of analysis leads to a technocratic approach to urban accessibility. With this line of thought, travel is reduced to a physical, material relation to the environment. Yet surely any progress through public urban space also involves meeting other citydwellers and communicating through speech and body language? It must therefore be plausible to posit the idea of public sociability linked to urban wayfaring.

Work on ethnomethodology and urban sociology attest to the collective dimension of mobility (Ryave and Schenken, 1975; De Certeau, 1984; Livingston, 1987; Coulter and Parsons, 1990; Lee and Watson, 1993; Bordreuil, 2005). Travel, whether it takes the form of a stroll, a trip to the shops or just passing movement brings city-dwellers into relation with one another. However, such situations of co-presence make passing vulnerable: there is a risk of bodies colliding; everyone is exposed to the others' gaze. But public order is very rarely disturbed by situations of bodily and visual accessibility. Why is this the case? The work of Goffman $(1963,1971)$, alongside that of Whyte (1980) or Lee and Watson (1993) reveals the existence of rituals governing social life. With regard to pedestrian traffic, a range of procedures are used to reduce the risk of shocks, keep movement fluid and allow overtaking. So, the 'sliding step' technique is widely used in crowds. This entails 'a slight inclination of the body, rotation of the shoulder and an almost imperceptible sidestep' (Goffman, 1971: 14). Such manoeuvres go hand-in-hand with visual orientation strategies, the purpose of which is to limit public encounters to a fairly superficial plane and allow all parties to keep up appearances. So, a civil lack of attention prevails (Goffman, 1971): each person anticipates at a distance the action of others and takes care, in the stream of unfocused interaction (not requiring any engagement), not to catch their eye. This particular mode of observation enables each one to understand and anticipate the other's trajectory, adjust their own course and action, and lastly to categorize the individuals present in any space. According to Lee and Watson (1993) such visual orientation strategies take various forms: pedestrians may choose to see but also to scrutinize or simply glance at others. Furthermore, such behaviour seems to be directly connected to motor action: a pedestrian's route is organized by the direction of his or her gaze, while at the same time, the direction in which they walk determines the focus of their gaze. In some cases, this visual organization of pedestrians' line of conduct may give rise to social formats (Lee and Watson, 1993): objects or devices which, on account of their visual configuration, organize motion. For example, spotted at a distance a queue obliges pedestrians to wait behind the last person and not to try to squeeze in further along. In this respect, such visibility of the public urban space is not to be taken as an instrument for the normalization or control of social life. In a much broader sense it constitutes a resource on which city-dwellers may draw to move around in compliance with the rules of civility in public. 
This approach has the advantage of updating the accomplished, situated and collective character of urban travel: the public conduct of people, regardless of its nature, is reciprocally adjusted to suit the place where it occurs and what pedestrians mutually opt to display. This perceptual organization of social life modifies courses of action and shapes the environment to form multiple perceptual milieus (Coulter and Parsons, 1990; Mehta, 2008; Thomas, 2010). In this sense, urban accessibility cannot be conceived as being pre-defined; it organizes itself through the action of city-dwellers. Here again, can one assume that urban accessibility is only dependent on the visual modality? Can one reduce the role of pedestrians' perceptual activity simply to one of framing their actions?

\section{The effectiveness of architectural and urban ambiences}

Our analysis seeks to provide answers to these questions. It follows on from this work in social science while also adopting an ecological approach. Two hypothesis underpin our thinking. The first one concerns the commonly established connection between urban accessibility and mobility. From our point of view accessibility to the public urban space depends more on the motivity of pedestrians than on their mobility. By motivity we mean the primal, immediate human act by which we inhabit space and time. So motivity does not necessarily require movement in space, unlike mobility. Nor does it always fulfil a practical purpose. Motivity engages the senses, body and attention of the pedestrian more than mobility. De facto, it requires various perceptual, bodily and social attitudes to be actualized. Our second hypothesis concerns the nature of and role played by the sensory modality in this access to the city: urban accessibility involves a dynamic process which needs to be revealed and which depends just as much on the resources of the sensory environment as on the perceptual activity of the pedestrian.

In the past few years the research works from the field of the architectural and urban ambiences highlighted the effectiveness of architectural and urban ambiences. An ambience results from the perceptual organization - both sensory and cognitive - or an expert production and/or a technical device; in practice it exists when an assembly of knowledge and know-how is perceived in a characterized space-time, social, cultural context inscribed in an objectivizable given (Augoyard, 1998). These works show that an individual's (visual and/or sonic, tactile, thermique...) surroundings contribute to positioning them in space and to their action. More specifically ambience organizes their perceptual activity, contextualizes practice and supplies a potential for use. The effectiveness of ambience is apparent both in the social practices of pedestrians and in their motor actions. However, it is uneven: each ambience, in so far as it brings into play one or more sensory modalities in combination, plays a specific part in each of these practices.

Furthermore, their operationality often depends on the context in which city-dwellers act and use them. As part of an acousmatic experience of the world (in other words hearing a sound without seeing its source) sound may for instance be taken as a vector for verbal communication: it enables individuals to communicate with one another despite the fact that the surroundings do not allow them to make themselves mutually accessible by sight. Sound also plays a part in the recomposition of urban territories. Analysis of the soundscape, Augoyard (2006) shows how manipulation of the surroundings or sonic objects makes it possible to play on the distance (or proximity) between people and redefine the spatial limits of a place. 'The distribution of the sonic forms of a place does not necessarily correspond to what the visual organization suggests [...] The sonic map of a town, in the mind of a city-dweller, is a here-and-there based on a qualitative rationale; people associate or categorize places according to their sound quality: an area with noisy places, another with tranquil spots' (Augoyard, 2006: 18). In a different register, work on underground spaces (Chelkoff 
and Thibaud, 1996) reveals the part played by the sensory environment in movement. According to these authors visual perception has a motor component: any visual and/or lighting configuration brings into play, much as other sensory modalities, pedestrians' perceptual activity, their ability to act and their relation with others. For example, some lighting configurations challenge the visual acuity of pedestrians, upsetting their stride: a ceiling light reflecting on the ground causes the visual space to dilate vertically leading to ambiguity regarding the nature of the material on which pedestrians are supposed to be walking'. In contrast, other configurations exaggerate the legibility of space and the direction of pedestrians. 'The blind subway corridors connecting to the Grand Louvre [museum in Paris] are almost an injunction to keep moving, due to the powerful directionality of the space produced by the narrow passage and the line of light on the ceiling, with no eye-catching objects or inscriptions, or obstacles on the ground and opaque surfaces delimiting a very restricted field of vision' (Chelkoff and Thibaud, 1996: 82). From this point of view, accessibility to the public urban space relates simultaneously to:

- a principle of physical opening of the place to city-dwellers. This is a reminder of an early definition of the term: accessibility, from accedere, to approach, where one can accede, which is open or sensible to something, which does not present any hindrance and which is within the grasp of someone (after the Dictionnary Larousse 2017),

- a regulatory principle for pedestrian traffic,

- an organizing principle for the modes of co-presence in public.

But our analysis goes further. From our point of view, urban accessibility represents a perceptual accomplishment: over and above motor and civic skills, it brings into play the senses of pedestrians and engages multiple perceptual procedures. Accordingly, when crossing a street without the help of a crossing with lights, pedestrians' hearing plays as important a part as their visual acuity and/or ability to accelerate their pace, because hearing tells them about the possible presence of vehicles and their speed. In the same way, in a crowd, pedestrians actualize visual and/or kinaesthetic skills: anticipating at a distance and with a single glance the trajectory of others; avoiding collisions, sometimes without even looking, while paying attention to air turbulence caused by others' movement. These kinesic skills, displayed by pedestrians, were brought to light following a study of obstacle-detection modes deployed during urban trips by people who have been blind from birth. This study (Supa et alli, 1944) revealed that they have the ability to 'perceive facially' bulky, immobile obstacles in their way: the sensation of a slight pressure on the forehead, probably caused by air turbulence, provides clues as to the presence and location of such obstacles. In 'ordinary' pedestrians, the supremacy of sight overrides this facial perception. Furthermore, this perceptual accomplishment seems to be situated in time and space: it is contextualized in so far as pedestrians act as a function of their social surroundings and the (sensory, built and conceptual) qualities of the setting; it also has a temporal framework given that the perceptual, social and motor skills are actualized in the dynamic of the journey and depending on its sequentiality.

In practice, this perceptual accomplishment is formalized by the configurative activity of pedestrians. The term 'configuration' is used here as originally defined, abstracting itself from the many meanings it has been given in disciplinary fields as varied as poetry, psychology or indeed sociology. The notion of configuration refers to the process by which any city-dweller, in the course of a journey, shapes their environment. So it does not relate to the idea that stable data exist somewhere in the space, but rather that the space is in a state of constant creation. Three steps, inherent to the sequentiality of an urban journey, organize this configuring activity:

- In the first step, on entering a site, pedestrians select one or more noticeable sensory phenomena. This is also an opportunity to allocate a particular identity to each of the places through which they pass. Each place will stand out, to a 
pedestrian's ear and subsequently in their memory, for the force and specialness of its sonic environment; it will thus remain designated as a marketplace, for instance, not so much because of the trading which actually occurs there in the morning but rather because of the mixture of voices and noises which seems to characterize it.

- In the second step in this work of configuration pedestrians can combine a site's sensory qualities: practically speaking this involves highlighting the most operative sensory modality (or modalities) for accessing both the space and others. The second step occurs as pedestrians immerse themselves in the space. In this case their perceptual activity has nothing to do with registering psychic content; it is much more a way of grasping the space as an object, depending on specific situations. So, for example, pedestrians in a hurry will probably prefer a smooth road surface, so they can accelerate their pace without the risk of tripping. Similarly, young children will probably take advantage of a street with an echo which preserves the intelligibility of their words, enabling them to play at a distance while trading insults.

- The third and final step involves a process of incorporating in movement and exchange the potential for action afforded by the sensory environment. In this respect, the third step bears out the relation of co-determination between the perceptual construction of the relation to place and urban practices. In other words, this 'sensory shaping' of the public urban space is embodied in the conduct of pedestrians: in the dynamic of the urban journey itself, affecting both the motor action of pedestrians, their modes of perceptual attention, gestures and posture in space. For example, places perceived as being overcrowded often give rise to conflicting behaviour: the crowd forms a mass, the physical proximity of bodies forces each person to contract inwards, only moving their upper limbs, their feet barely moving, with increasingly frequent glances right and left, and (visual and sonic) attention scanning all round to anticipate the reaction of others at a distance. In contrast, less crowded places produce a sense of well-being: the pace of walking slows, bodies seem relaxed and supple, attention drifts.

From this point of view, pedestrian accessibility to the public urban space is subject to this configuration process. The (partial or total) failure of this process will give rise to a disabling situation. For example, proliferation of the sensory stimuli in a single place seems to upset the configuration process in pedestrians: the selection and composition steps are impeded; perceptual powers focus on the need to avoid obstacles and adjust behaviour to the surroundings. On the other hand, a successful configuration process gives rise to an 'enabling' situation. In this case the sensory environment of the public urban space represents a fund of resources for pedestrians, facilitating the three steps in the configuration process. Pedestrians can easily focus their attention, organize their practices and the contexts in which they take place.

\section{Conclusion}

This article tests thinking on pedestrian accessibility to public urban space against ordinary situations encountered by city dwellers. Our purpose is to reverse the direction taken by current thinking in order to centre it on the particular experience of the disabled as they travel from one point to another. We also seek to refocus debate on the issue of pedestrian mobility, its diversity, the skills it brings into play, the links it necessarily makes with the surroundings and the community at large. This line of reasoning leads to two conclusions, making the subject more complex.

On the one hand, in practical terms, we question the idea of accessibility as something unique and pre-defined by the physical and conceptual qualities of urban space. Similarly, our study throws doubt on the normalization of design rules and the rigid 
solutions they sometimes impose. It shows, on the contrary, the extent to which pedestrian access to the city is the result of an ongoing process of creation: depending on time and place, and the presence or absence of a crowd, the pedestrian will adjust his or her action to suit the characteristics of their surroundings. This way of 'acting' (out and on) the environment is the result of a dynamic configuration process, carried out in the course of each urban journey. It engages both the senses of the passer-by and the potentialities afforded by the sensory environment. In other words, pedestrian access to the city results from permanent adjustment between these potentialities and conducts. The sensory process remains variable: for each sense, there is a corresponding manner of apprehending space and giving shape to the contexts of action. In this sense, there cannot be an ideal or model design solution, suited to each situation.

In the field of design, receiving this type of result upsets acquired knowledge and habits. By proposing, finally, a matrix for reading and assessing space perceived in motion, we question firstly the basis for thinking which focuses essentially on the techniques by which passers-by move around. The accessibility of a place is as much the result of its capacity to facilitate physical movement by humans as its propensity to allow the co-existence of various modes of inhabiting and configuring space. More than just physical access to public urban space by the pedestrian, what matters is to take into account his or her perceptual access and the capacity of the surroundings to 'connect' them. Similarly, by putting the emphasis on the three steps in the configuration process, we address an often neglected aspect of pedestrian accessibility to the city, namely its temporal dimension. The space of perception in motion definitely seems to be a shifting space, its form recomposed, its qualities re-appraised with each succeeding step. Practical questions therefore face urban planners, as how best to design and layout the space-time of urban travel?

Secondly in conceptual terms our study highlights the practical dimension of situated perception: the configuring activity of the passer-by enables him or her to decipher their surroundings, to find their way, to move onwards and comply with the rules of civility commonly accepted in public.

In this sense perception is limited neither to a role of information nor yet to one of framing ordinary activities: it instruments pedestrian access to the city and even organizes the contexts of action. The pedestrian's physical and perceptual accessibility does not only concern urban mobility: perception acts on pedestrian progress just as much as it does on the modalities of their meeting or co-existence with others. At the same time our study draws attention to the (motor and social) efficacy of the sensory environment, the latter being both the medium and the matrix of urban practices. In other words, the sensory environment of urban public space exerts a spatializing and socializing power over the pedestrian's ordinary practices. Earlier work in the field of the architectural and urban ambiences revealed the potentialities of the sonic or visual environment; the present study supplements them by highlighting in particular the role of certain audiovisual configurations in the passer-by's onward movement and the shaping of their relation with others. It also prompts new thinking on the importance of the tactile modality (podo-tactile but also kinesic, haptic and proprioceptive) in pedestrian access to the city. In each case, the quality of these sensitive configurations promotes the comfort of the pedestrian: it increases the clarity of the space, facilitates its orientation, allows to catch the best "affordance".

Finally, in terms of methodology, there is a heuristic merit in the detour via a disabled person's experience of moving from A to B in order to conceptualize urban accessibility for all. By questioning the validity of a specific feature of disabled movement, we are able to draw attention to the diversity of modes for accessing space. From this standpoint 'the handicap' (every bit as much as the habilitation) constitutes one degree among others in urban accessibility'. In aging societies such as ours, it is a universal 
experience that needs to be taken into account in order to improve the quality of our urban public spaces and so, the well-being of users. Encouraging thought on situations in which perception is problematic raises the question of the right to be different and the necessary re-specification of the language of accessibility.

\section{References}

Augoyard, J. F. 2007. Step by Step: Everyday Walks in a French Urban Housing Project. Minneapolis: University of Minnesota.

Augoyard, J. F. 2006. Sonic Experience.A Guide to Everyday Sounds. Montréal: McGill Queen's University Press.

Augoyard, J. F. 1998. "Eléments pour une théorie des ambiences architecturales et urbaines." Les cahiers de la recherche architecturale, n42/43, pp.13-23.

Bordreuil, J. S. 2005. "Culture, attentions visuelles et orchestrations des mobilités." In Les sens du mouvement, edited by S. Allemand, F. Ascher and J. Lévy, pp. 207-215. Paris: Belin.

Blackman T., Mitchell L., Burton E., Jenks M., Parsons M., Raman S. and Williams K.. 2003. "The accessibility of public spaces for people with dementia. A new priority for the open city." Disability and Society 18, pp. 357-371.

Careri, F. 2002. Walkscapes. Walking as an aesthetic practice. Barcelona: Gustavo Gili.

Chelkoff G. and Thibaud, J.P. 1997. Ambiances sous la ville. Une approche écologique des espaces publics souterrains. Grenoble: Cresson.

Coulter, J. and Parsons, E.D. 1990. "The praxiology of perception: visual orientations and practical action." Inquiry. An interdisciplinary Journal of Philosophy 33, pp. 251272.

De Certeau, M. 1984. "Walking in the City." The Practice of Everyday Life. Berkeley: University of California Press.

Gibson, J. J. 1979. The ecological approach to visual perception. Boston MA: Houghton Mifflin.

Goffman, E. 1971. Relations in public. Microstudies of the public order. New York: Basic Books.

Goffman, E. 1963. Behavior in public places. Notes on the social organisation of gatherings. New York: The Free Press.

Hinchliffe, S. and Whatmore S. 2006. "Living Cities: Towards a Politics of Conviviality." Science as Culture 15, pp. 123-138.

Holland C., Clark A, Katz J. and Peace S. (2007). Social interactions in urban public places. Bristol, UK: Policy Press.

Imrie, R. and Kumar M. 1998. "Focusing on disability and access in the built 
environment." Disability and Society 13, pp. 357-374.

Jenkins G.R, Yuen H.K and Vogtle L.K. 2015. "Experience of Multisensory Environments in Public Space among People with Visual Impairment". International Journal of Environmental Research and Public Health, 12(8), pp. 8644-57.

Katz, J., Holland C., Peace S. and Taylor E. (edited by I. Blood). 2011. A Better Life what older people with high support needs value. New York: Joseph Rowntree Foundation.

Kitchin, Rob (1998). "Out of Place, Knowing One's Place: space, power and the exclusion of disabled people“. Disability and Society, vol.13, Issue 3, pp. 343-356

Lauria, A. 2017. "Tactile Pavings and Urban Places of Cultural Interest: A Study on Detectability of Contrasting Walking Surface Materials“, Journal of Urban Technology, vol.24, Issue 2, pp. 3-33.

Lee, J. R. E. and Watson, R. 1993. Interaction in public space: Final Report to the Plan Urbain. Paris: Plan Urbain.

Levy, E. 1994. "L'accessibilité à l'épreuve." Gare du Nord: mode d'emploi (edited by I. Joseph). Paris: Plan Urbain, RATP, SNCF, pp. 181-240

Livingston, E. 1987. Making sense of ethnomethodology. London: Routledge.

Low, S. and Smith, N. 2006. The politics of public space. New York: Routledge.

Mehta, V. 2008. Walkable streets: pedestrian behavior, perceptions and attitudes. Journal of Urbanism: international research on placemaking and urban sustainability, vol.1, Issue 3, pp. 217-245.

Ryave, A. L. and Schenken, J.N. 1975. "Notes on the art of walking." Ethnomethodology, Selected readings (edited by R. Turner). New York: Penguin, pp. 265-274.

Sanchez, J. and Velche, D. 1996. Vécus et usages de la gare de Lyon par des personnes handicapées. Paris: CTNERHI.

Solnit, R. 2001. Wanderlust: A History of Walking. New York: Penguin.

Shortell, T. and Brown, E. 2014. Walking in the European City: Quotidian Mobility and Urban Ethnography. Farnham: Ashgate.

Supa Michael, Kotzin Milton \& Dallenbach, Karl (1944). « Facial vision: the perception of obstacles by the blind » dans The american journal of psychology, 53 (2), pp. 133183.

Talen, E. 2002. "Pedestrian access as a measure of urban quality". Planning Practice and Research, 17 (3), pp. 257-278.

Thomas, R. 2010. "Architectural and urban atmospheres: shaping the way we walk in town.” PQN Final Report Pedestrians' Quality Needs (edited by R. Methorst, H. Monterde i Bort, R. Risser, D. Sauter, M. Tight and J. Walker). European Science Fondation: COST, pp. 54-68. 
Thomas, R. 2005. Les trajectoires de l'accessibilité. Bernin: A la Croisée.

Van der Linden, Dong V., and Heylighen, A. 2016. From accessibility to experience: Opportunities for inclusive design in architectural practice. Nordic Journal of Architectural Research, Issue 2, pp.33-58.

Whyte, W.H. 1980. The social life of small urban spaces. New York: Project for public space Inc. 